\title{
Howard E. Brandt, Ph.D.: Personal recollections
}

\author{
Samuel J. Lomonaco 1
}

Soon after joining the Signal Processing Group of Army Research Laboratory in Adelphi, Maryland (ARL-Adelphi), in 1983, I happened to be walking down one of the many hallways of ARL-Adelphi when somehow I met up with Howard Brandt. After a brief exchange of the usual initial greetings, our conversation turned to a discussion of his research work in relativity. I soon learned that his research was on a generalization of general relativity along the lines of Kaluza-Klein theory. Instead of the usual spacetime metric tensor, he was focusing on a metric tensor that not only involved spacetime, but also included four velocity and Andrei Sakharov's maximum acceleration hypothesis. This in turn led to a spacetime manifold based on Finslerian Geometry.

We decided to continue our conversation in the ARL cafeteria. Over a cup of coffee, he queried me about my research interests. So I in turn talked about my research program in algebraic and differential topology and higher-dimensional knot theory. Much to my surprise, he was intensely interested, frequently interrupting my explanation with delving questions. And so a long-term friendship was born.

Prof. Lomonaco authored the main article and Prof. Myers authored the addendum.

$凶 \quad$ Samuel J. Lomonaco

lomonaco@umbc.edu

1 University of Maryland Baltimore County (UMBC), Baltimore, MD 21250, USA 


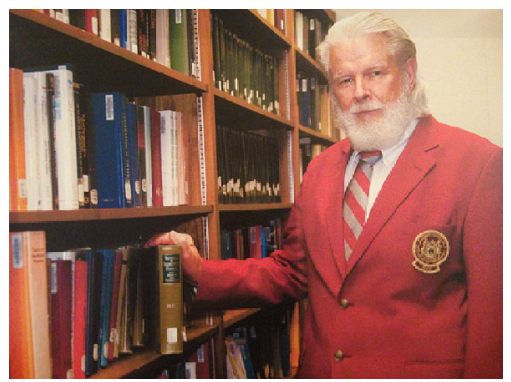

Howard Brandt in his MIT blazer at the ARL-Adelphi Library holding Morse and Feshbach's Methods of Theoretical Physics.

In 1985, I left ARL-Adelphi to accept a full professorship at the University of Maryland Baltimore County (UMBC). As much as I enjoyed being at ARL-Adelphi, UMBC had made me an offer that I could not refuse. Soon after joining UMBC, I received a phone call from Howard suggesting we should meet the next Saturday at his home office to have a "Congress." I had no idea what he meant by a "Congress," but I was game. Why not? I accepted his invitation. I was soon to find out.

That Saturday, I arrived at his doorstep promptly at 1 PM for a "Congress." He greeted me at the door with a cup of coffee and immediately ushered me downstairs to his home office. Entering his office for the first time was a surprising encounter. Books, papers, and journals were piled high everywhere. Fortunately, enough room had been left to provide for a narrow path to a small area with a desk, two chairs, and a blackboard. A discussion then began about his work in relativity and continued with great intensity.

The only way I know how to describe what happened is to compare our repartee with an intense game of racket ball. In this instance, Howard made the first volley by writing some equations on his blackboard, challenging a response as our discussion ricocheted between the walls until I was forced to return the volley by writing another equation on the blackboard. The game went on that Saturday, only with occasional interruptions to replenish our coffee cups. I learned an incredible amount that day. Finally, the "Congress" ended promptly at 5 PM. I had learned the true meaning of a "Congress!” I was intellectually exhausted.

The first "Congress" was so successful that the next month I invited Howard to have another "Congress," this time at my home office. The "Congresses" continued almost monthly for more than 25 years, alternately meeting in each of our home offices, until Howard passed away in 2014. As time went on, the books and papers in his home office encroached more and more on our working area, until finally we were forced to move the "Congresses" at his residence to his dining room table.

A different topic was designated for each "Congress." The chosen topics ranged from topics in general relativity, quantum mechanics, quantum field theory, classical mechanics, thermodynamics to topics in knot theory, algebraic topology, differential topology, group representation theory, algebraic geometry, and theory of computation.

For one "Congress," Howard chose a topic I had only vaguely heard about, quantum cryptography. This in turn led to many other future "Congresses" dedicated, not only to quantum cryptography, but also to Quantum Computation and Quantum Information 
Science. Motivated by this endeavor, I organized and led an American Mathematical Society (AMS) Short Course on Quantum Computation at the Annual Meeting of the AMS held in 2000 in Washington, DC, thereby formally introducing quantum computation to the mathematical community for the first time. This endeavor was highly successful, more than I could have possibly anticipated. Of course, Howard, who spoke on Qubit Devices, was one of my invited course speakers. Together, we also organized and led an AMS Special Session on Quantum Computation at the same meeting.

All this was the beginning of an ongoing research program in Quantum Information that continues to this day. Many books and published papers resulted from and continue to result from the research program, many of which are joint with Howard. This in turn led to our involvement in the DARPA QuIST Program. It was during one of the DARPA QuIST meetings that Howard introduced me to his good friend and now my good friend John Myers. John has added a number of his own personal recollections of Howard in the Addendum to this paper.

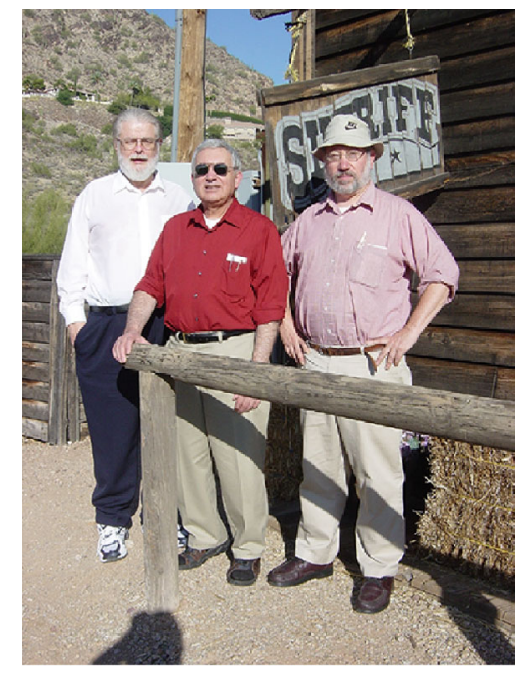

Session break during a DARPA QuIST meeting in Scottsdale, Arizona. Middle, "Sheriff" Sam Lomonaco, with his two "deputies," left Howard Brandt and right Lou Kauffman.

It is important to mention that Howard had many interests other than physics and mathematics, as expressed in his many hobbies, such as classical music, oil painting, philosophy, poetry, psychology, and chess. His favorite composer was Bela Bartok. He used the piano to compose many musical pieces. For me, the most impressive was the one written in the style of Bela Bartok. Howard produced a number of oil paintings, many of which could be found somewhere among the books and papers in his home office. One of his favorite artists was Amedeo Modigliani.

Howard was an avid fan of Ludwig Wittgenstein. Once when we were both attending a two-week quantum information workshop in Cambridge, England, he insisted that we go on an expedition to search for Ludwig Wittgenstein's grave. After an intense search of Cambridge, we found the grave. Howard then immediately pulled out of 
his pocket a copy of the Tractatus Logico-Philosophicus and ceremoniously in a loud booming voice read a number of excerpts from the book.
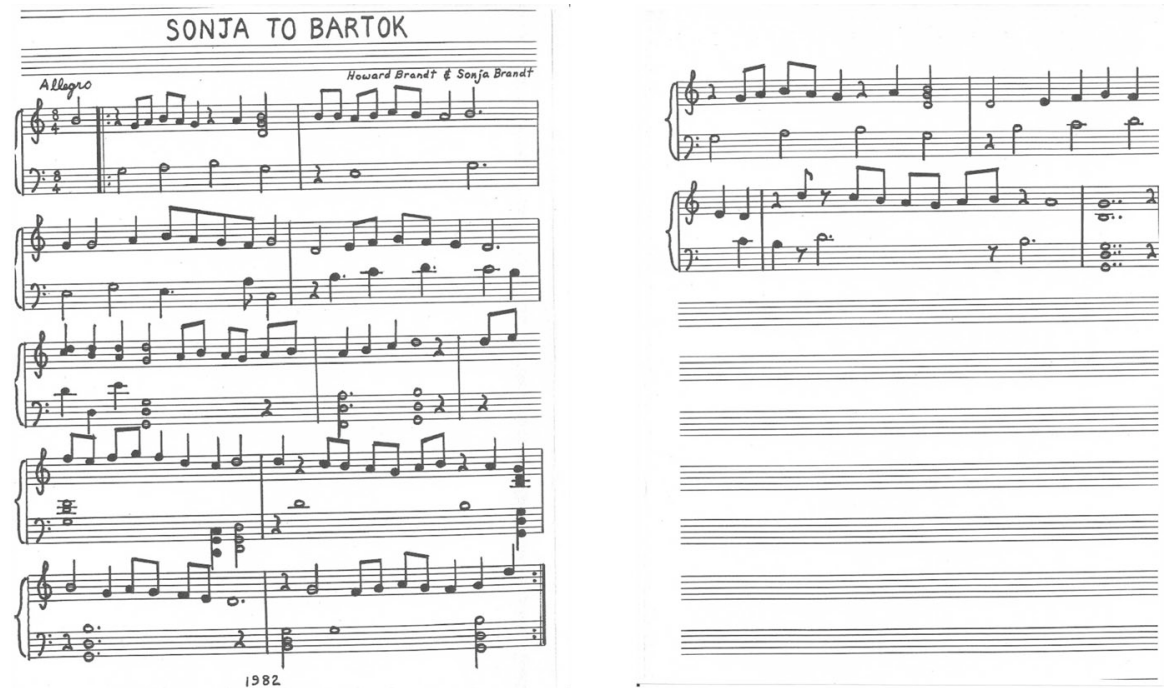

A musical composition written by Howard Brandt and his daughter Sonja Sweterlitsch, compliments of his daughter Karen O'Connor.

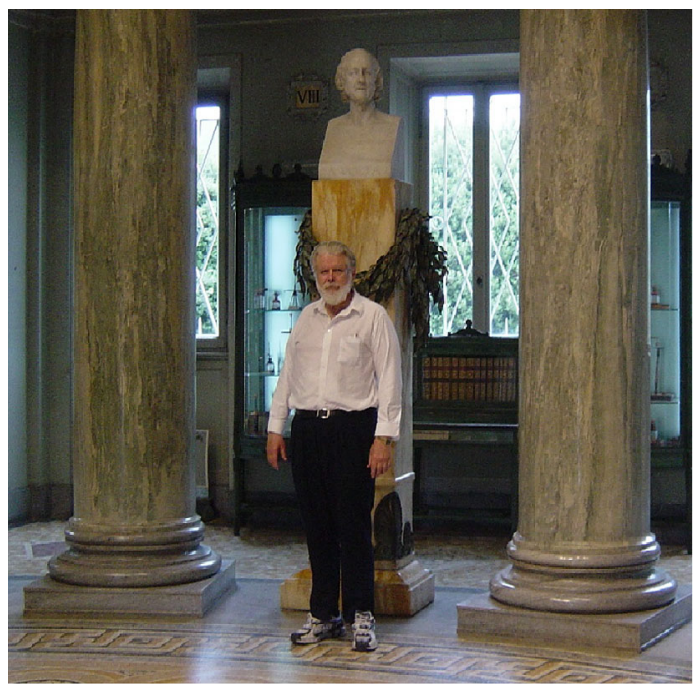

Howard Brandt at the Volta Museum in Lake Como, Italy. (2005) 
Howard was a fierce chess player whose tactic was to intimidate his opponent by any means possible, frequently contorting his face in a threatening fashion and slamming down his pieces.

Each time he would visit his alma mater MIT, Howard would always find an opportunity to read poetry out on the MIT green. T.S. Eliot was one of his favorite poets.

Toward the end of his life, Howard became intensely interested in the works of Carl Gustav Jung, frequently discussing Jung's book, Memories, Dreams, Reflections.

One of my last encounters with Howard was in his hospital room, the day after his quintuple bypass surgery. Much to my amazement, he was sitting up in his chair next to his bed working feverishly, performing his Editor-in-Chief tasks for the journal of Quantum Information Processing. It was almost as if, as soon as he woke up from surgery, he immediately started back on his editorial tasks. Unexpectedly, Howard passed away two months later on April 13, 2014.

Finally, I am reminded by a gift from Howard, given a few weeks just before his surgery, that he was a deeply religious person. There it is, hanging on my wall, a copy of a painting by Johann Schmittner, Our Lady Undoer of Knots.

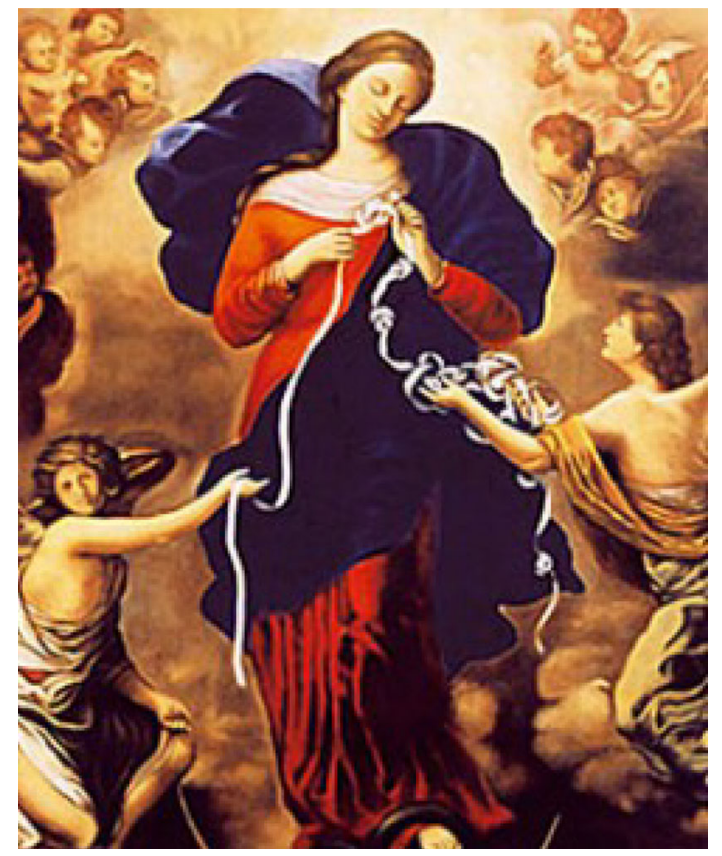

Our Lady Undoer of Knots by Johann Schmittner 


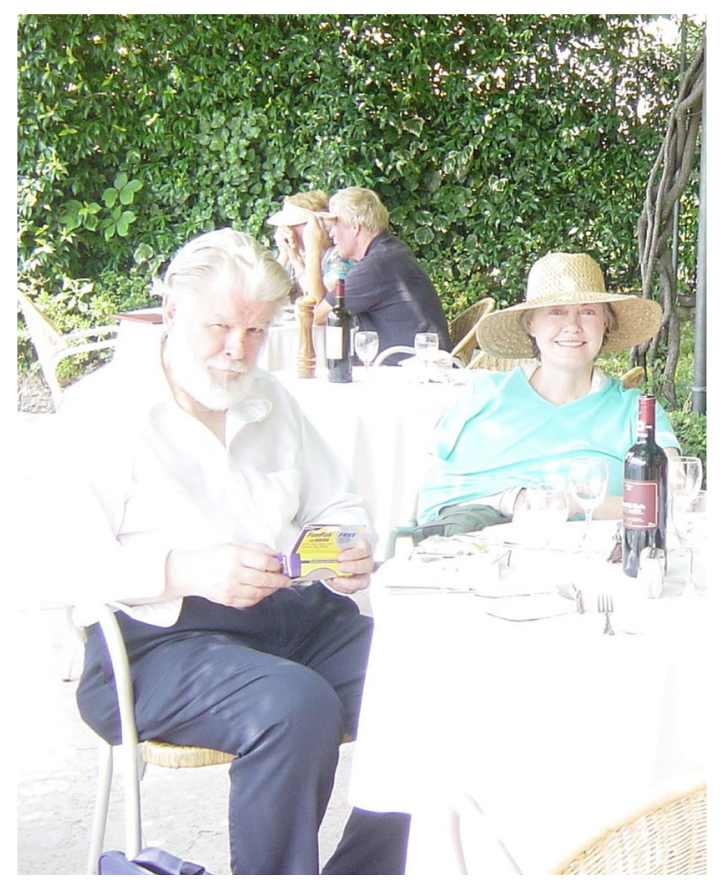

Lake Como, Italy, Howard and Marilyn Brandt. (2005)

\section{Addendum: Personal recollections by John Myers}

I met Howard in the 1980s when he was managing a program for the Strategic Defense Initiative. Prof. Tai Wu and I were briefing Howard on our progress on a project having to do with electromagnetic radiation which involved complex calculations. From experience with other managers, in our presentation we minimized the technical detail. Howard promptly and vigorously objected that he wanted nothing left out. He wanted the whole story with detailed derivations. Tai and I were stunned. After we recovered, we actually enjoyed Howard's attention to the fine points. That began a happy association that lasted from the 1980s until Howard's death.

I also worked with Howard in other ways: as a Project Manager for the subsequent High-Power Microwave program, as an organizer for SPIE conferences, and as a coauthor. Howard's vigorous presence at conferences was unforgettable, the way he would stir up an audience, challenge a speaker, or put matters in perspective.

It was a pleasure and an honor to participate with Howard in writing papers, several of which were published in the Physical Review A. He and I also co-invented and patented a positive-operator-valued-measure receiver for quantum cryptography. Much of the joy of working with Howard was his passion-passion he brought to physics, to dinner time topics of philosophy and art, and to his wife and two daughters of whom he was most proud. 